\title{
Introduction
}

\section{Making Aid Conditional}

"This is probably the root of intergenerational poverty," said [World Bank President Jim] Kim. "Stunted women who are malnourished become pregnant. Just because they were stunted and malnourished doesn't mean that their children have to be, but they probably end up not having sufficient nutrition when they are pregnant and they give birth and their children are stunted and it just goes on."

FROM AN EXCLUSIVE PUBLISHED IN THE GUARDIAN.

In July of 2013, I huddled closely with Yesenia, a mother of two and a respected community leader. We sat on a low wooden bench in the quiet green courtyard behind her home, high in the brown mountains of Andean Peru. I met Yesenia while doing research on the gendered impacts of Peru's conditional cash transfer program, Juntos. Like most of the other women in the village, Yesenia received a small cash payment every two months from Juntos, so long as she met a number of conditions related to her children's use of health and education services. I had called Yesenia earlier that morning, hoping for one last visit before I left Peru for the United Kingdom, where I would write up my research findings. Yesenia was unusually upset when she answered the phone, so I immediately caught a rumbling combi (minibus) to the village near her home. Along the way I met Yesenia's young neighbor Judit, who was my research assistant, and we ascended the hill to Yesenia's earthen home on foot. We found Yesenia alone under her Andean eggplant tree, folded over in despair. Yesenia confided that she had been diagnosed with breast cancer. Sobbing, she clutched my hand to her breast, asking if I could feel the noxious lump.

Yesenia was a reserved, strong woman. Once trained by a nonprofit organization as a community health worker, she now ran the state day-care program out of a room with a packed-earth floor in her two-story house, work that was unpaid but which allowed her an opportunity for self-development. Her kind husband 
migrated to the far-away coast for work, which meant that she was the primary caregiver for her two children. As we sat in her garden, Yesenia explained to me that the nearest cancer treatment center was in Trujillo, a ten-hour journey by bus from her village. Going to Trujillo would mean leaving her two children behindbut who, she wept, would care for them? There was also the issue of financesYesenia's Juntos payment would not cover the cost of living in the city while she accessed treatment.

Later, Judit and I descended the hill from Yesenia's house. At seventeen, quiet Judit was perceptive. When she did get talking, she was often frank. Breaking the silence we held on our walk, Judit remarked that for rural women in such circumstances as Yesenia, "the only option is to die or hope that God saves you."

Grounded in the stories of women like Yesenia, this book provides an alternative view of one of the fastest-growing new measures in global health and development: making aid conditional. From Mexico and Brazil to Indonesia and New York, relief from the most acute impacts of poverty is often made conditional upon the capacity of the poor to demonstrate their willingness to lift themselves out of poverty. Conditional cash transfer (CCT) programs, which The Economist magazine crowned in 2010 as "the world's favorite new anti-poverty device," provide poor households with cash incentives to adopt the health- and education-seeking behaviors that development experts see as imperative to improving their lives.

\section{THE EVIDENCE FOR CCTS}

At the 2017 World Economic Forum, World Bank president Jim Kim praised the Peruvian CCT program Juntos for its impacts on malnutrition and economic growth: "We're going to say to every country in the world that has a problem with stunting, we're ready to bring you the Peru formula. We're willing to provide financing for these conditional cash transfers. CCTs are great anyway. They help poor people. They stimulate the economy, they are a great thing to do." Over the past decade and a half, CCTs have been lauded by some of the world's most powerful development actors. In 2004, the president of the Centre for Global Development proclaimed that CCTs were "as close as you can come to a magic bullet in development." By 2017, sixty-seven countries had implemented at least one conditional cash transfer program, a figure that is up from two countries in 1997 and which has doubled since 2008 (World Bank 2017). In Latin America alone CCTs reach over 135 million people (Stampini and Tornarolli 2012).

Enthusiasm for a conditional approach to poverty relief is grounded in an extensive and compelling research literature documenting the immediate impacts of CCTs on children's interactions with health and education services. Jim Kim's recent statements reflect Peru's applause-worthy reduction in stunting, from 30 percent in 2007 to 17.5 percent in 2013, as well as a reduction in neonatal and under-five mortality (Huicho et al. 2016). This decline coincides with the 
introduction of Peru's CCT program, Juntos, a World Bank-supported program intended to tackle the acute impacts of poverty.

CCTs originated in Latin America, and today they are among the most evaluated social programs on the planet. The majority of evidence on CCT impacts comes from the Mexican program now called Progresa, which is one of the earliest, and now largest, CCTs. Regular evaluations were built into the program administration at the outset, and this set a significant precedent. Today, we have a robust body of evidence that policy makers draw on to maintain and expand existing programs and to support implementation of new initiatives. Most of the available evidence derives from quantitative research, especially experimental methods such as randomized control trials and quasi-experimental methods (e.g., regression discontinuity, propensity score matching, instrumental variable, and difference-in-differences; Lagarde et al. 2007; Leroy et al. 2009; Kabeer and Waddington 2015). This literature is largely concerned with measuring primary program objectives related to household consumption and the uptake of health and education services. While acknowledging some variation related to program design, the existing quantitative evidence tells us that CCTs are, overall, effective and efficient mechanisms for altering the health- and education-seeking behavior of poor households.

For instance, regarding health and nutrition, we know that CCTs are effective at increasing utilization of health services (Gertler 2000; Attanasio et al. 2005; Levy and Ohls 2007; Galasso 2011) and increasing household food consumption (Hoddinott and Skoufias 2004; Angelucci and Attanasio 2009; Resende and Oliveira 2008; Handa et al. 2009). Where CCT programs have been implemented with the goal of reducing maternal mortality, they have effectively increased pregnant women's use of health services, including antenatal care and in-facility births (Lim et al. 2010; Glassman et al. 2013). CCTs have been linked to a reduction in neonatal, infant, and child mortality and, in particular, deaths attributable to poverty-related causes such as malnutrition and diarrhea (Barham 2011; Rasella et al. 2013). CCTs have been shown to produce better growth outcomes in children (i.e., reduction in stunting; Gertler 2004; Fernald et al. 2010; Andersen et al. 2015; Kandpal et al. 2016) and improvement in children's motor skills and cognitive development (Fernald et al. 2008). Both outcomes are likely related to uptake of health services and increased household consumption. CCTs have also been successfully deployed to increase vaccination rates for such diseases as tuberculosis, measles, diphtheria, pertussis, tetanus, and polio (Morris et al. 2004; Barham 2005; Barham and Maluccio 2009).

Regarding the aim of building human capital through education, studies show that CCTs are effective at increasing school enrollment (Schultz 2004; Sadoulet et al. 2004; Behrman et al. 2005; Cardoso and Souza 2003; Dammert 2009; Attanasio et al. 2010). As is the case with health service usage, there is some variability related to gender, age, ethnicity, and location, but overall the evidence indicates a positive 
uptake. A study in Mexico found that CCTs effectively reduced both the gender gap and the ethnicity gap in school attendance (Bando et al. 2005). Relatedly, in a number of cases CCTs have helped reduce child labor, while not eliminating it entirely (Schultz 2004). CCTs show a particular propensity for reducing boys' participation in paid labor (Sadoulet et al. 2004; Behrman et al. 2005) and girls' unpaid domestic labor (Skoufias et al. 2001). Of course, the size of the incentive influences the reduction in labor participation-if it is not large enough to replace lost wages, children continue to work (Cardoso and Souza 2003).

CCTs have also been linked to some significant "spillover" impacts. While they are not designed as traditional safety net programs, which help beneficiaries weather shocks or crises such as illness, loss of employment, or natural disasters, CCTs can serve as a sort of "insurance" in such times. For example, modest cash transfers have the effect of smoothing consumption patterns in some households. Practically speaking, this means that even in relatively harder times, more people can find enough food to eat without relying on coping mechanisms with negative long-term impacts, such as selling assets or removing children from school (Maluccio and Flores 2005).

In summary, whether we look at consumption, health appointments, or school attendance, we know that CCTs are often highly effective at achieving the program's primary aims, at least in the short-term. Drawing on this data, CCT proponents suggest that cash incentives are an efficient mechanism for interrupting the intergenerational cycle of poverty. The sum of money that these programs transfer to poor households is relatively modest for the sizable increase in service utilization that they are able to generate. As a result it is understandable that Jim Kim and many others sing the praises of CCTs and advocate making aid conditional as a vital new measure in attempts to solve the problems of poverty.

Yet proponents have a number of concerns, and some quantitative researchers are beginning to turn their attention toward these questions. For instance, the jury is out with respect to whether we should attribute efficacy to all or just some common elements of program design (Leroy et al. 2009; de Brauw and Hoddinott 2011). While some research stresses the role of conditionality, other studies point to the increase in household income, or the health and nutrition trainings tacked on as complementary program elements. Generalized claims about the positive economic impacts of CCTs have been questioned on the basis that most evidence to this effect comes from the Mexican program and may not hold for other countries (Kabeer and Waddington 2015).

Some researchers have also begun to draw a question mark over long-term outcomes. The evidence that we do have on sustained impact is at best mixed and remains largely inconclusive. Increasingly, this literature concedes that in addition to quantitative increases in health and education service usage (i.e., more people attending school and health appointments), the quality of those services also influences the substance and durability of positive outcomes (Cecchini and 
Soares 2015). For instance, even in cases where CCTs have had significant positive impacts on use of antenatal care services and in-facility births, researchers emphasize the need for women who attend health facilities to receive at least minimumquality obstetric care (Lim et al. 2010).

Yet as mature and rigorous as the quantitative literature may be, comparative statistics cannot grasp all that we may learn from the experiences of women like Yesenia. Quantitative research has taught us little about the side effects or unintended consequences of making aid conditional. Most program evaluations focus on outcomes for children, and so we know very little about efficiencies with respect to household budgets or impacts on gender relations. Conspicuously absent from much of the quantitative evidence base and related policy literature is a substantive grappling with the fact that CCT programs rely on women's unpaid labor. Mothers are typically expected to do the work of meeting program conditions, while fathers are typically entirely absent from program design. Can we say confidently that CCTs are efficient when viewed from the perspective of the mothers who must meet program conditions? Probably not, if we rely only on quantitative findings. While comprising a much smaller body of literature, qualitative social science research has drawn attention to a number of gaps not tackled by the more dominant quantitative approach.

The available qualitative research draws a critical question mark over the capacity of CCTs to have "transformative" effects on the systems and structures that produce poverty in the first place (Molyneux et al. 2016; Hickey and King 2016). The research does not deny positive impacts outright; rather it draws out nuances that are more difficult to capture in bigger and more rigid data sets. For instance, ethnographic research reveals that CCT recipient communities use the programs to improve the conditions of their lives in ways that the government never intended. In northeastern Brazil, savvy recipients capitalize on the increase in local bureaucratic infrastructure to advocate developing a community development agenda that meets their needs (Garmany 2017). Yet this positive microscale impact has less to do with conditionality itself and is likely better attributed to an increase in decentralized state intervention.

While qualitative research from a critical feminist perspective has acknowledged some improvements to individual women's economic empowerment, it is much more skeptical of the capacity of CCTs to transform the root causes of women's poverty and subordinate social status. A set of qualitative studies focused on these questions reveals how CCT programs often place blame for poverty on poor mothers and generate an undue burden on women's time (Best 2013; Bradshaw and Víquez 2008; Cookson 2016; Corboz 2013; Gammage 2011; Hossain 2010; Molyneux 2006; Molyneux and Thomson 2011; Nagels 2014; Tabbush 2011).

The available feminist research raises important questions requiring further quantitative and qualitative inquiry. These include, but certainly are not limited to, women's time use, household budgets, gender relations within households, power 
dynamics within communities, interactions between women and state institutions, impacts on ethnic and racial relations, and the gendered implications of rural program implementation. Unfortunately, the concerns raised in this body of evidence have yet to exert substantial influence on program design, raising questions about knowledge translation and why some forms of knowledge are considered so much more authoritative than others.

It is reasonable to suggest that the dominant quantitative mode of evaluating CCT impacts has created what we might refer to as systematic blind spots (a term I borrow from Salmaan Keshavjee 2014), particularly as they relate to the experiences of the mothers responsible for meeting program conditions. As I argue throughout this book, attending to these blind spots will force us to reframe our understanding of the effects of conditionality, as well as the sense in which conditionality is "efficient." To begin the project of addressing these blind spots, we need to first trace the reasons why conditions were adopted in international development and social policy.

\section{CONTEXT: MAKING AID CONDITIONAL}

Despite the force of capital and conviction behind a global project of "development" over the past half century, poverty persists.

GILBERT RIST, “DEVELOPMENT AS BUZZWORD," 2010

I arrived in Peru's capital city, Lima, in the thick of a heavy, seasonal sea-mist fog that locals fondly refer to as la garúa. ${ }^{1}$ It was September 2012, and I was there to study the country's largest social intervention, a conditional cash transfer program called Juntos, which in English means "Together." Visible through the dense gray were brightly colored billboards and banners advertising new investments in social programs. A little over a year earlier, Peruvian voters had elected a centerleft president named Ollanta Humala, who had campaigned on a platform of "social inclusion." The thrust of his inclusive agenda was a promise to provide the historically poor and marginalized majority with a bigger stake in the country's recent and rapid economic growth. In Humala's election, Peru joined the ranks of other Latin American countries, like Bolivia, Ecuador, Nicaragua, and Argentina, in swinging to the left, ushering into power candidates cozy with the Chavistastyle governance of pro-poor Venezuela.

One of Humala's first acts as president was to create the Ministry of Development and Social Inclusion (MIDIS), which was to oversee a number of social programs that would help deliver on his campaign promises. The largest program to come under MIDIS's purview was Juntos, which at the time was six years old. Policy makers told me that the social programs that had come before Juntos were more akin to handouts and were prone to corruption. In contrast, Juntos helped the poor to help themselves. At the time, Peru was one of the more recent countries 
to jump on board a trend sweeping through the region: providing poor mothers with cash payments on the condition that they invest in the health and education of their children.

In some respects CCTs were the practical expression of a wider contextual shift in international development thinking. During the 1980s, the development paradigm in Latin America was driven by the Washington Consensus, which encompassed a set of neoliberal structural adjustment policies imposed by the World Bank and International Monetary Fund. Among other things, structural adjustment policies devolved responsibility for welfare to communities and households by stripping away public supports and making services such as health care and education privately provided-and in many cases, prohibitively expensive (Bakker and Gill 2008). Women bore the brunt of this policy shift as they assumed responsibility for an increased burden of care work (Elson 1995; Benería 1999). As time passed, social indicators, including progress toward the UN Millennium Goals, showed deterioration in the livelihood conditions of women and children, rural populations, and ethnic minorities (UNDP 2003). By the 1990s, rates of poverty and inequality had risen starkly in Latin America and globally, leading some to term it a "decade of despair" (UNDP 2003).

The period that followed is often referred to as the "post-Washington Consensus" (Stiglitz 1998). Authoritative development institutions, the World Bank foremost among them, shifted focus to redressing the devastating impacts of austerity and privatization through a raft of social policies (Barrientos et al. 2008; Molyneux 2007; Ruckert 2010). Social policy encompasses the political organization of all that is necessary to produce and maintain a healthy, productive population, including social assistance and insurance, health care and education (see Mahon and Robinson 2011; Ruckert 2010). On one hand, the World Bank continued to emphasize the privatization of services related to health and education (Pearce 2006, as cited in Ruckert 2010). On the other hand, it promoted and financed "social inclusion" programs that were intended to ensure health and education coverage for "excluded" groups that could not afford or access market-based services (Roy 2010; Ruckert 2010). ${ }^{2}$ The logic driving this response understood poverty and exclusion as resulting from an individual incapacity to participate in the labor market because of a lack of human capital—the skills, experience, and good health gained through education and access to preventative care. Governments throughout Latin America adopted variations of an "inclusive development" framework combining market-driven macroeconomic policy with social policies targeting rural populations, indigenous groups, and other poor people (Grugel and Riggirozzi 2009; Macdonald and Ruckert 2009; Andolina et al. 2009; Yates and K. Bakker 2014).

Within this "inclusive" shift, conditional cash transfers surfaced as the policy tool of choice (Ruckert 2010; Cecchini and Madariaga 2011). The first CCT programs emerged in Mexico (Prospera, subsequently renamed Oportunidades 
and later Progresa) and Brazil (Bolsa Familia) in the mid-199os. These programs responded to criticism from funders and the public that social programs were often poorly targeted, were inefficient with regard to administrative expenditures, and did little to interrupt the intergenerational transmission of poverty (Rawlings and Rubio 2005). From the outset, CCTs used census data to target only those households identified as poor. With some variations, CCTs involve the payment of a small sum of money-an incentive-to poor families on a monthly or bimonthly basis. The cash is contingent upon the fulfillment of certain programmatic conditions intended to build children's human capital, such as school attendance and use of health services, and pregnant women's attendance at prenatal appointments.

Most CCTs enlist mothers as the cash recipients, because women tend to be the children's primary caregivers and are considered more likely than men to invest the cash in the household. The programs claimed to overcome previous inefficiencies in social welfare by requiring beneficiaries to be active participants in the achievement of program goals (Molyneux 2007). This does not mean that CCTs are an example of a participatory development or "active citizenship" approach that attempts to grant community members agency and voice in projects intended to improve their well-being (see Hickey 2010). Rather, CCT program goals and the conditions intended to achieve them are set by experts and implemented by teams of program staff, who do not consult the mothers responsible for ensuring they and their children attend services in a timely manner. Research among women CCT recipients in Uruguay, Nicaragua, Mexico, and Peru has shown that women participate under intense social pressure to be "responsible" mothers and good community members, even when meeting program conditions places unreasonable demands on their time and resources (Molyneux 2006; Bradshaw and Víquez 2008; Corboz 2013). Nevertheless, the nature and breadth of the action required-of women-is not often questioned in public conversations, which tend overwhelmingly to laud the merits of conditional aid.

The early Mexican and Brazilian programs have undergone a number of transformations related to targeting and administration. They have also grown exponentially. In Brazil in 2016, nearly 55 million people-one-quarter of the population-lived in households enrolled in Bolsa Familia. In Mexico, that figure was 29 million, also nearly a quarter of the population (ECLAC 2018). The rapidity with which CCTs have spread globally has led economic geographers Jamie Peck and Nik Theodore to characterize them as "fast policy" (Peck and Theodore 2015a). Building on the momentum of the Mexican and Brazilian experiments, regional experts travel to Africa, South and Southeast Asia, and even New York to share technical knowledge and assist in the implementation of new programs. Today, with the technical and financial support of the World Bank and other international development agencies, variants of CCT programs reach more than half a billion people. 


\section{THE THEORETICAL UNDERPINNINGS OF CCTS}

CCTs draw on conventional economic theory, which posits that people make rational decisions based on a cost-benefit analysis using the information they have available to them (Medlin and de Walque 2008). As a "demand-side" intervention, CCTs are recognized as a mechanism for helping people overcome financial barriers that may affect their decision to access education and, even more so, health services (Ranganathan and Lagarde 2012). For instance, cash transfers may help families pay for education, health care, or medications when these goods are not free. They may also defray the indirect costs of using health services, for example those associated with transportation. Writing about global health programs more generally, medical anthropologist Paul Farmer has discussed such practical and unavoidable expenses as the donkey transfer fee (Farmer 2003, 149). If a family cannot well afford the trip to and from the health clinic, they may choose to forgo care even when it is "free" upon reaching the clinic, especially if that care is preventative rather than curative.

Finally, according to mainstream economics, cash transfers may help mitigate opportunity costs-the potential income forgone through spending time accessing services rather than on revenue-generating activities. All of these cost-mitigating benefits can easily be attributed to households having more cash on hand. In many places in the world, cash transfer programs that do not impose specific behavioral conditions do exist on a considerable scale. Why, then, impose conditions?

There are a few reasons. Evidence suggests that conditional cash transfers can correct "misguided beliefs" held by the poor that serve as barriers to their good health and education (Fiszbein et al. 2009; Gaarder et al. 2010). Another theory upon which CCTs are based comes from the field of behavioral economics: that most people are not very good at making upfront investments in order to obtain modest future benefits. ${ }^{3}$ Sometimes this is because of deep-seated cultural beliefs. For instance, skepticism in response to vaccination, and a preference for educating boys instead of girls (because the latter are more likely to work in the home), are driven at least in part by culture but end up affecting public health and gendered rates of poverty. Behavioral economists suggest that the use of a "nudge" can correct for irrational beliefs and shortsighted decision making (Thaler and Sunstein 2008). CCTs are a great example of a nudge at work. Using the case of vaccinations and girls' education, a moderate cash incentive can help nudge individual households to seek preventative health care and educate all children through to graduation.

Another reason for imposing conditions is that they represent a form of "social contract" between providers and recipients of social assistance. CCTs are guided by the notion of "coresponsibility," or a shared responsibility between household and state for overcoming poverty (the Peruvian CCT is called "Together" for just this reason). Some types of social support, such as welfare payments, charitable 
handouts and food stamps, do not typically include a specific element of accountability on the part of recipients. In contrast, CCTs require households to demonstrate a certain set of behavioral changes deemed necessary for improving their circumstances. They must actively demonstrate a willingness to improve their own lives by meeting specific conditions. In Peru and many other countries, these conditions are referred to as "coresponsibilities."

\section{RESPONSIBLE MOTHERHOOD}

The gendered policy preference for mothers, instead of fathers, to receive the cash transfer has social implications. Women are held responsible for meeting the program conditions, or coresponsibilities, and so must organize their time and labor around ensuring that these are met. In communities where Juntos is implemented, mothers often commented upon the responsible or irresponsible behaviors of their female neighbors and fellow Juntos recipients, mostly in relation to how they cared for their children. Researchers interested in the gendered impacts of CCTs in countries other than Peru have questioned the ethics of interventions that devolve responsibility for overcoming poverty to poor mothers and, in the process, produce sticky social norms related to "responsible motherhood" (Molyneux 2006; see also Bradshaw 2008).

These critiques merit attention. Should a mother's poverty really be taken as evidence that she acts irresponsibly? At a moment when her own health was in question, Yesenia's most urgent concerns revolved around who would care for her children if she were unable. Cases such as hers challenge the prevailing assumption in contemporary development and social policy that poor women need incentives to properly mother their offspring. Even before Juntos, Yesenia did everything within her means to ensure the survival of her children, whom she raised largely on her own. She took advantage of opportunities for training and microentrepreneurship, volunteered her labor to provide community services, and now faithfully met the conditions that Juntos required. By all accounts, she already was the sort of responsible mother that development experts hope to achieve through use of behavioral incentives.

Responsible motherhood in rural Peru manifested itself in a number of unintended ways. When witty, twenty-six-year-old Josepa was pregnant with the second of two children, she was abandoned by her husband for a younger woman. Faced with few options, pregnant Josepa left her philandering husband and moved back in with her parents in a village some three hours away. Like other families in the village, Josepa's parents were subsistence farmers, and on their property was a great granadilla tree that produced a sour-sweet fruit that her children devoured. One afternoon as we sat in the yard, Josepa explained to me that she had been receiving the Juntos payments for nearly eight months. When she moved back to the village, her sister had been enrolled in the program, and Josepa had hoped for 
the day that the census takers would come by and register her details. Sure enough, one day they arrived, and in due course she was summoned to a community meeting and asked to provide the required documentation so that she could enroll in the program.

Given that there was no other paid work available, Josepa was grateful for the "little bit of help" that the cash payment provided. In order to receive Juntos's monthly payment of one hundred soles (thirty-five US dollars), mothers like Josepa were required to meet a standard set of seemingly reasonable conditions. These included attendance at prenatal exams, children's regular growth-and-nutrition checkups until the age of five, and school attendance with fewer than three absences per month until eighteen years of age or graduation. Program implementation and compliance with conditions was monitored by frontline program staff called local managers. ${ }^{4}$ Given that one of Josepa's children was under five, and the other just over, she was required to meet both the health- and education-related conditions. The local managers would record Josepa's compliance, and if she did as required, she would join the majority of her neighbors, who received monthly

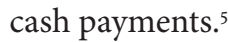

Over the course of my ethnographic fieldwork with women in the Andes, I discovered that the practice of providing and earning a cash incentive did not play out exactly as policy makers intended. Juntos recipients like Josepa were made to believe that their coresponsibilities extended far beyond the reasonable set of conditions laid out in official policy documents. In the villages where I conducted research, responsible motherhood involved much more than the use of basic health and education services on behalf of one's children. It also required participation in a whole host of activities deriving from more powerful people's ideas about what it takes for rural families to overcome their poverty-or in more sinister cases, activities that helped authorities maintain and acquire more power. When I asked Josepa what she had to do to receive the "little bit of help" that Juntos provided, she responded, "Whatever the local manager tells me to." Josepa, like all of the other Juntos mothers I spoke with, did not have a clear picture of what was officially required of her, because she was not provided one by the authorities entrusted with implementing the antipoverty program. In fact, the system of imposing conditions in the rural countryside was so distorted by program staff and other local authorities that none of the Juntos mothers I met knew what the program conditions "officially" entailed.

In addition to the requirement that children attend school and health appointments, women in my interviews cited a variable combination of activities. I call these shadow conditions. These activities included having hospital births rather than home births; growing a garden; keeping hygiene instruments (toothbrush, soap) organized; cooking for the school lunch program; having a latrine; leaving babies at the state day-care center; participating in parades; painting the Juntos flag on the outside of one's house; marching to demonstrate support for a 
politician's reelection campaign; contributing toward the medical costs incurred when a neighbor breaks a leg; having a cocina mejorada (smokeless stove); contributing funds for school parties; participating in a regional cooking fair; and attending literacy workshops. None of these were official policy requirements, and at first I thought that these women were simply wrong. However, after month of these conversations I began to see that this was a systematic tendency; in all of the interviews I conducted, women named at least two of these tasks; typically they named four or five.

In practice, Juntos mothers often found these other tasks indistinguishable from official conditions. This was through no fault of their own, as shadow conditions were often organized by local program managers, teachers, health clinic staff, and local government authorities, who used threats of expulsion from the program in order to get women to participate. As I elaborate in chapter 6, Juntos, like other CCT programs, was institutionally organized in a way that granted local managers the discretion to enforce shadow conditions. While women's participation in "extra," "voluntary," or "community" tasks has previously been documented in a small number of CCT evaluations, it has rarely been treated as a matter of significant social concern. This book breaks with tradition by demonstrating that shadow conditions are a manifestation of the coercive power of incentives in a context of deep social and economic inequality. As one employee of a grassroots NGO that worked with rural communities commented to me, this was Juntos at its most "perverse."

How can we understand the experiences of women like Yesenia and Josepa? How can the everyday lives of poor mothers reorient our interpretation of all the data that tells us CCT programs are "a great thing to do"? In the following section, I argue that quantitative surveys and experiments should be interpreted in light of a deep grounding in local historical context and slow, nuanced, ethnographic fieldwork.

\section{AN INSTITUTIONAL ETHNOGRAPHY IN PERU}

I arrived in Peru in 2012, right around the time that tech mogul turned philanthropist Bill Gates told the Spanish newspaper El Pais that Latin American countries should no longer receive international aid. Gates used Peru as an example, referring to it as a "middle-income country" with a wealth of mineral resources to exploit. There was no reason, he claimed, that Peru should not be "as rich as a European country" (Aguirre et al. 2012). While perhaps true in theory, this kind of statement renders invisible key drivers of poverty and inequality like colonialism, global capital, and the power and greed of richer countries. It also sidelines the very real issue of inequality within countries. Like many Latin American nations, Peru is unevenly developed. ${ }^{6}$ While the country possesses, as Gates says, a wealth of natural resources and has the gross domestic product of a middle-income nation, its riches are not evenly enjoyed. Peru's landscapes reflect stark inequities 
in investment and, as a result, quality of life. The coastal region of Peru-where Lima is located-has a much lower overall incidence of poverty than the central mountainous region and the humid tropical forest region referred to as the selva. The Peruvian government took these geographical inequities into account when deciding to implement Juntos in the rural sierra and selva but not the more urban coastal region.

Analyses of cash-based aid frequently overlook the geographical particularities of the communities and broader regions in which CCT programs are implemented. As a result, we risk developing blind spots that conceal the ways that geography and policy collide to produce unintended consequences-positive and negative alike. The spaces and livelihoods across which Juntos is designed and implemented are exceptionally diverse not only in terms of climate, geography, and demographics but also in terms of infrastructure, industry, and employment. In the section that follows, I introduce the research sites, situating these in relation to the much larger, unevenly developed national landscape.

\section{Peru, an Unevenly Developed Country}

This study was conducted in two regions of the country: metropolitan Lima, where Juntos was designed and is administered, and the department of Cajamarca, one of the rural areas where Juntos is implemented. Cajamarca is situated high in the northern Andean mountain range. Research there was conducted in two districts, which I have renamed to preserve their anonymity: Labaconas and Santa Ana, both of which are located over two thousand meters above sea level. ${ }^{7}$ Within these, I conducted observations and interviews in the district capitals and a handful of villages of varied size. This region of the country, known as the sierra, has a geography, economy, and social landscape that differ from those of the coastal and Amazon regions.

Historically, Cajamarca was a key site of the Spanish conquest. It was in Cajamarca city in 1532 that the last Inca king, Atahualpa, was killed by Spaniard Francisco Pizarro in a brutal massacre of Inca peoples. This battle led to three hundred years of Spanish colonial rule and a sweeping transformation of precolonial culture. By the late nineteenth century, the majority of Cajamarcan residents were Spanish speaking and identified as mestizo rather than indigenous. ${ }^{8}$ Livelihood patterns were also dramatically transformed. By 1940, approximately 28 percent of the rural population lived on haciendas (agricultural estates), a rate significantly higher than in any other Peruvian region (Deere 1990). Wealth was concentrated among a small number of hacienda landowners, who in turn controlled rural labor power. The hacienda class traced its origins back to Spanish rule and tended to follow familial inheritance practices, while its poorly remunerated labor was sourced from peasant families of indigenous or mestizo decent (Deere 1990). Under this arrangement, the region became a leading producer of grains, beef, and dairy; the latter in particular remains an important regional export commodity today. 


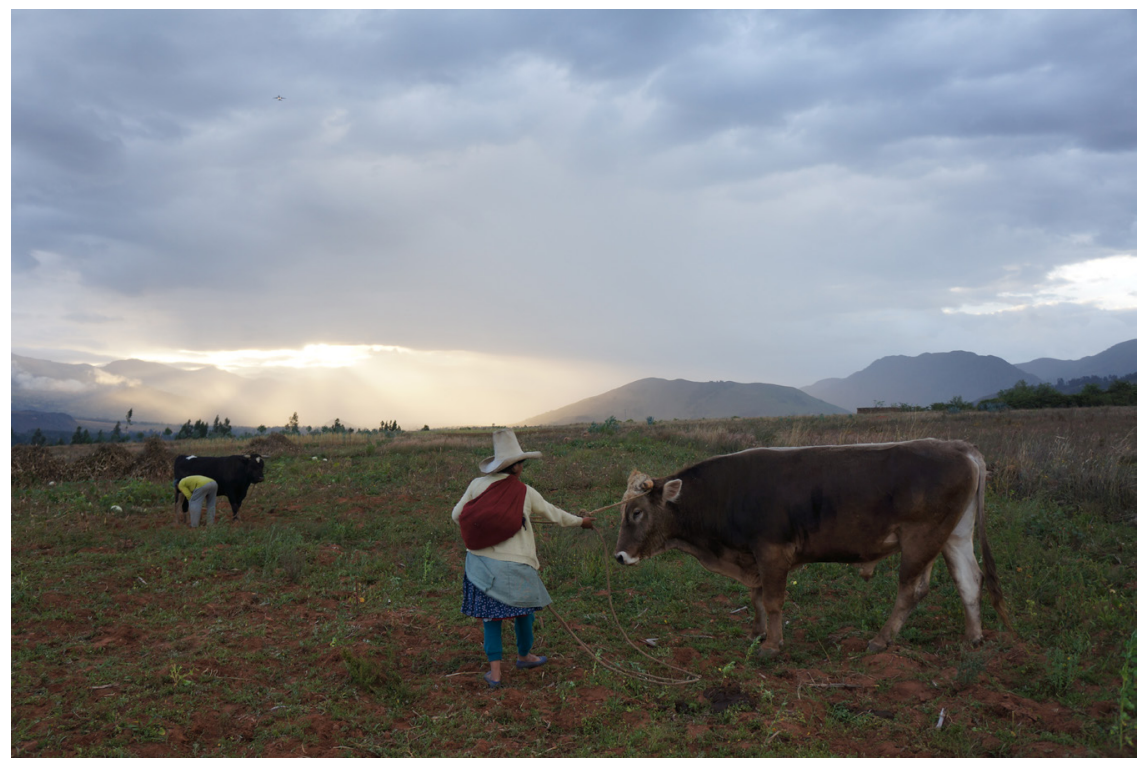

FIGURE 1. Grimalda and her husband guide her prized bull home after grazing. Photo by the author.

In the 1960 s and 1970s, agrarian reforms implemented under the Fernando Belaúnde and Juan Velasco governments changed the socioeconomic structure of the region. Landowners were forced to sell off their holdings or have them expropriated by the state, at which point the land was redistributed in small parcels to individual families who had previously been employed as laborers (Mayer 2009). This colonial legacy is evident today in the stratification between a largely mestizo, urban professional population, and a rural smallholder agriculturalist population. While large parts of the Andean and Amazonian regions are characterized as "indigenous," in the districts where I conducted fieldwork and across Cajamarca, the majority of indigenous descendants self-define as campesinos/campesinas, a term that indicates smallholders or peasant farmers and agriculturalists (figure 1). As descendants of Inca and other pre-Spaniard cultures, campesinos are an indigenous group recognized in national legislation and by the International Labour Organization's Convention 169. However, their historical relationship to land, their agricultural practices, and their engagement with market economies distinguish them from a number of other Peruvian indigenous groups (Ruiz Muller 2006).

The Andean sierra also bears the inequitable markings of global capital. For decades, foreign investment in the extractive industries has created landscapes of social stratification. The world's second-largest gold mine, Yanacocha, is a massive "open pit" situated at four thousand meters above sea level within one of the 


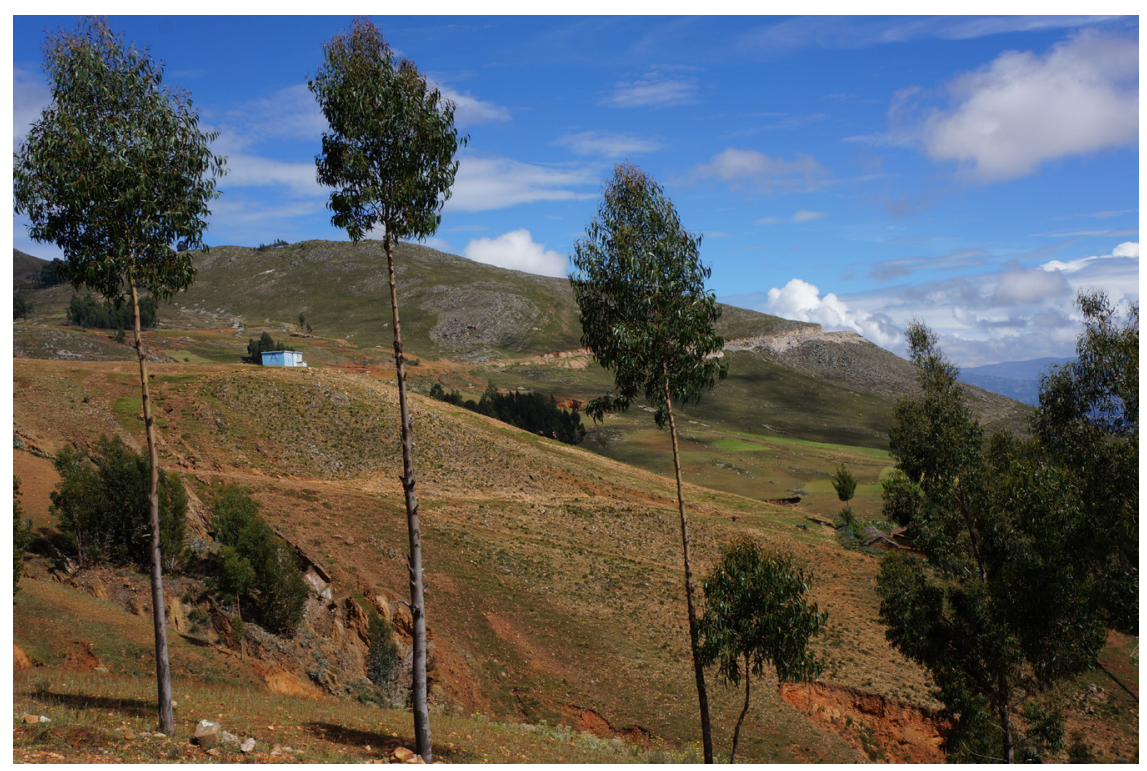

FIGURE 2. Public services do not reach all Andean households. Photo by the author.

poorest regions in the country. While Cajamarca city has benefited from a new private health clinic and international school, these perks are largely accessible only to the families of mine employees and those in the city who have in some way profited off the mine's existence. I attended the health clinic as a patient once, but none of the Juntos mothers who participated in my study were able to, owing to their low incomes and lack of health insurance.

In the highlands of the Peruvian Andes, CCT recipients are low-income, rural campesinas who have historically experienced exclusion based on their gender, class, and ethnicity and the geographical location of their homes. ${ }^{9}$ In 2013 , the poverty rate in rural Peru was 48 percent, compared to 16.1 percent in urban Peru (INEI 2014b). Cajamarca was (and remains) the poorest department in the country: in 2013, 52.9 percent of households were poor and 27 percent of households were extremely poor (INEI 2014b). Geographical disparities exist within the department itself. Wealth is concentrated in urban centers, and the poorest people live in the most isolated areas of the department (figure 2). Stark geographical inequities also exist in access to health care and education (INEI 2014b). In contrast to urban areas, health and education services in rural Peru are historically limited and of low quality. The symptoms of systematic underinvestment in vital services are dire. For instance, more than 50 percent of maternal deaths in the country are concentrated in eight of the twenty-four departments. All of these eight are rural, and Cajamarca department is one of them (UNICEF 2014). ${ }^{10}$ 
Such statistics ought to be unsurprising, given that rural women face significant barriers to health. In 2013, a national statistical survey found that 65.3 percent of rural women reported distance to the clinic as a barrier to obtaining health care, compared with 33.6 percent of urban women (INEI 2014a). After having overcome geographical hurdles such as lack of transportation, rural women also face the possibility that treatment may be unavailable. Absenteeism and understaffing in rural health clinics is a persistent problem in rural Peru, and 91.4 percent of women reported believing that there might not be anyone to attend them when they seek medical attention for an illness (INEI 2014a). While national health insurance is technically available to low-income Peruvians, it does not cover all medical costs. Nearly three-quarters of rural women reported that finding the money to pay for care when they were in need of medical attention was a problem (INEI 2014a).

Rural landscapes marked by poor infrastructure are a salient feature of this book. In rural Peru, only 56.6 percent of households have access to potable water, and only 46 percent have access to sanitary services (INEI 2014b). Inadequate infrastructure also affected how Juntos was implemented and what poor women were forced to do in order to earn their cash incentive. Transportation routes in rural Peru vary in availability, and fatal road accidents are common. In the districts of this study, some villages were at least partly connected to the district capital by a dirt road (figure 3 ). Women from those villages were able to use some form of communal transport on the days of the week in which this was available. Even so, access depended on the weather. As in much of the rest of the Peruvian sierra, during the rainy season-from October to April-these roads often became impassable. Other villages were not accessible by road and were connected to the district capital only by footpath. High rates of poverty in rural Peru drove the decision taken by policy makers to focus the implementation of Juntos in rural areas. Yet the research presented in this book shows how cash incentives do not necessarily eliminate geographical inequities and, in many cases, can actively exacerbate them.

\section{Programa Juntos}

Peru's CCT program is the Programa Nacional de Apoyo Directo a los Más Pobres, or "Juntos" (National Programme for Direct Help to the Poorest, "Together"). The program was created April 7, 2005, during the presidency of Alejandro Toledo. The Toledo administration found inspiration in the Mexican and Brazilian CCTs and proclaimed that Juntos would serve as a step toward tackling the country's serious inequality issue. Toledo garnered public and political support for the program by pointing to the international success of CCTs and the growing body of evidence indicating that CCTs were effective and efficient means of addressing poverty (Jones et al. 2008, 256).

The Juntos program vision is "to restore the basic rights of households whose members have regular access to quality basic services in education, health and 


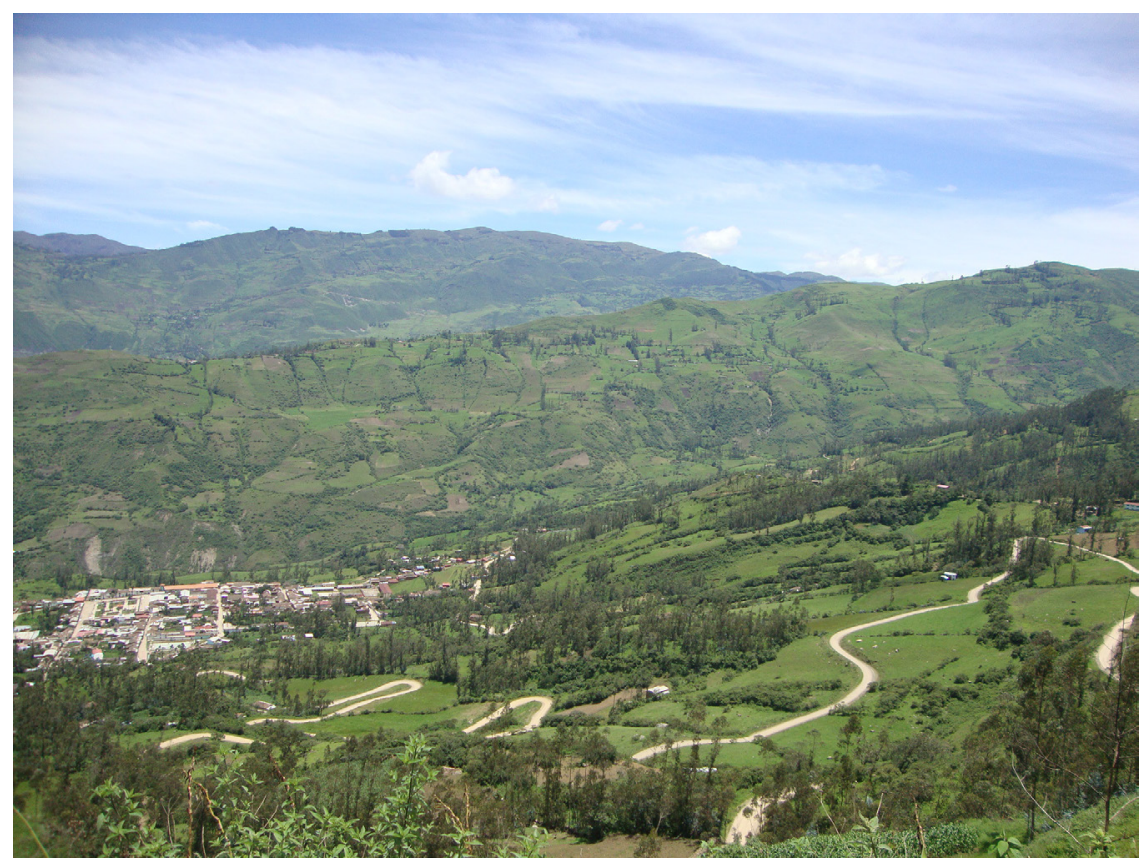

FIGURE 3. Villages where Juntos recipients lived were often connected to the services in larger populated centers by a single road or by footpaths. Photo by the author.

nutrition, corresponding to full exercise of their citizenship, and to improve their quality of life and human capital development, thereby reducing the intergenerational transfer of poverty" (Juntos 2015a). Juntos is meant to achieve this vision through two central functions. The first is through the direct transfer of monetary incentives to poor households in rural areas. The second is through use of conditions related to accessing health and education services (MIDIS 2012c). The policy-making and centralized administrative functions of Juntos take place in Lima, either at program headquarters or within the Ministry of Development and Social Inclusion, where Juntos has been housed since 2012.

Juntos determined household eligibility using data derived from the national census (Sistema de Focalización de Hogares). ${ }^{11}$ In order to qualify for Juntos, households had to meet a standard set of criteria: they had to have resided in the geographical area of intervention for at least six months; fall within the two poorest quintiles (poor and extremely poor); and have at least one person classified as an "objective member," which included pregnant women, and children or youth under nineteen years of age or not yet graduated from secondary school. Once a household had been determined to be eligible, all objective members were enrolled and a household representative, generally the mother, became a "Juntos user." By 


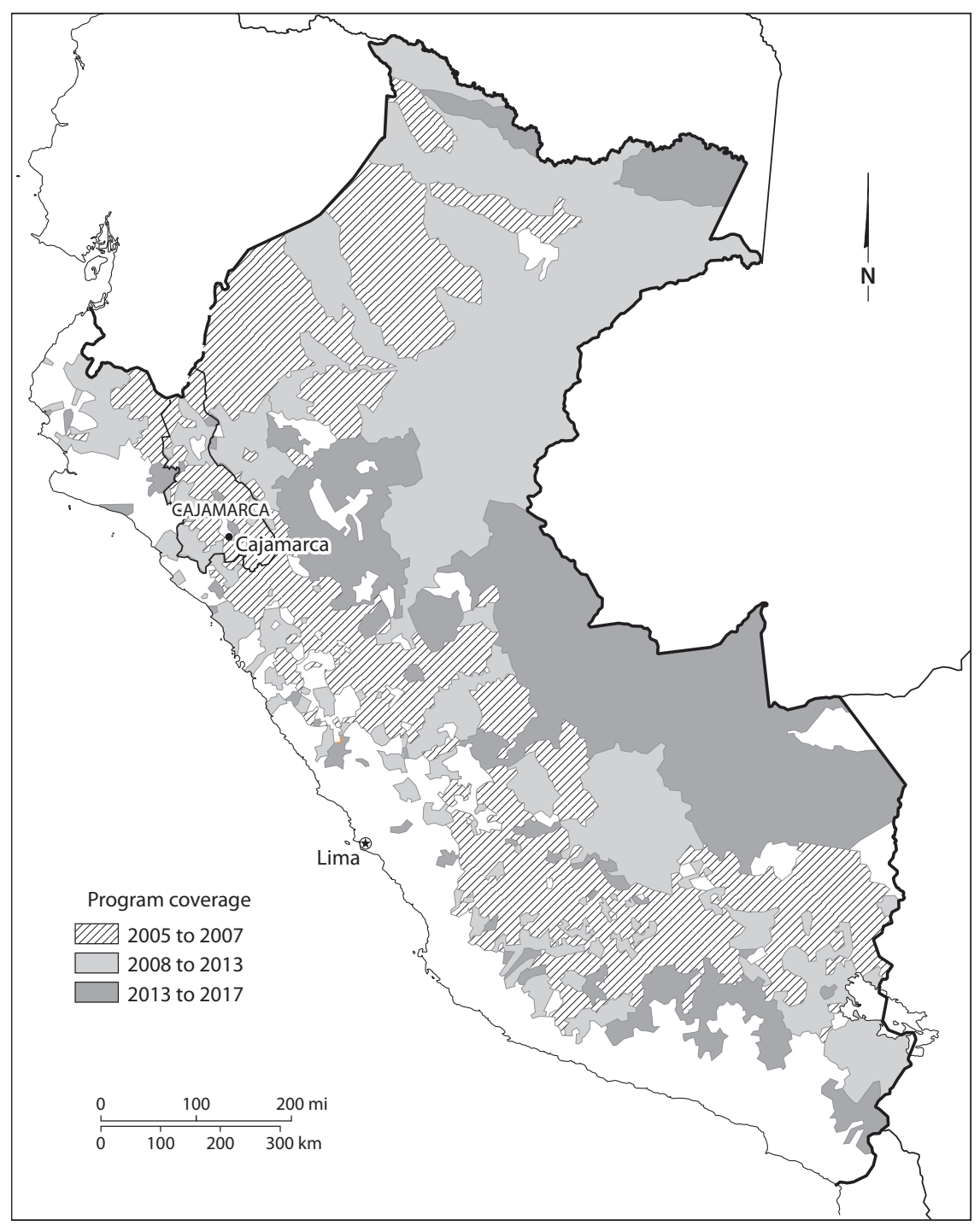

MAP 2. Juntos program coverage. Created by Bill Nelson.

the close of 2013, Juntos was the largest social program in the country, counting 718,275 affiliated households and reaching 1,553,772 children and 17,170 expectant women (Juntos 2015b). At the time, the program intervened in fourteen regions, 140 out of a total of 196 provinces, 1,097 districts, and 39,645 populated centers. Cajamarca had the highest number of CCT-affiliated households, so when I left Lima, that is where I went. 
Once a mother was enrolled in Juntos, she became responsible for meeting the program conditions, or "coresponsibilities." Juntos defined coresponsibility as "the responsibility shared between the household, whose members must use health and education services in an opportune manner according to stage in the lifecycle, and the state institutions which provide said services" (MIDIS 2013b). At the time of my research, health services included monthly prenatal exams for pregnant women; monthly checkups for children aged o-11 months; checkups every two months for children aged 12-23 months; and checkups every three months for children aged 24-36 months. It was expected that, at health appointments, children would receive nutritional monitoring, physical evaluation, immunization, and vitamin $\mathrm{A}$ and iron supplementation.

In the event that households had access to a certified early-childhood education center, children from 36 months to six years of age were required to attend, with no more than three absences per month. If the area of Juntos intervention did not have an early-childhood education center, households were still required to continue with regular health checkups. Mothers with children aged six to nineteen years old were required to ensure that the children attended classes; if a child was absent more than three times for no reason, mothers lost the next month's payout. ${ }^{12}$ Mothers were required to meet all of the conditions for each and every one of their children, with no exceptions. If a youth dropped out of school against his or her parents' wishes, which was not uncommon, the entire family was suspended from the program.

Whether or not conditions were met was monitored by local managers, who were frontline state employees. Generally educated at a technical school or university, these frontline bureaucrats traveled endlessly to clinics and schools to register households, collect attendance information about children, and enter all of the numerical data they gathered into a centralized computer system, which was based in Lima. Juntos recipients who met the conditions received a transfer, on the dia del pago (payday) as local managers and mothers referred to it, at a preestablished collection point. Normally, this was a National Bank branch; but in places without a bank, the state ensured delivery by armored truck. In some Amazonian regions with limited road access, the state delivered the monetary incentive by boat or airplane. Increasingly, program users were given debit cards and expected to withdraw the monetary incentive from a National Bank ATM.

In all cases, the local managers orchestrated the payday, insofar as they communicated to the mothers on which day it was to occur, made it known who would receive the payment and who would not, and organized the system of queuing mothers waiting for the cash (this is elaborated in chapter 4). In the first trimester of 2012, 95 percent of households nationally met the program conditions, fulfilling their share of the coresponsibility agreement. In Cajamarca, between 96 percent and 99 percent of affiliated households were recorded as having met the conditions and received the transfers (Juntos 2012). 


\section{Institutional Ethnography: An Approach to Accounting for Care and Power}

This book presents findings from a ten-month institutional ethnography of the Juntos program. Research took place between September 2012 and July 2013 and was divided between Lima and Cajamarca. I did not embark on fieldwork knowing that I would conduct an institutional ethnography. I had originally set out to understand how women experienced Juntos in terms of time use and access to public space, which I had planned to explore through a household survey, interviews, and observations. Yet as my fieldwork progressed, I pivoted in response to what I found.

In my first months of fieldwork in Lima, I interviewed current and former policy makers and program administrators at Juntos and MIDIS. I benefited from my tenure as an affiliate researcher at the Instituto de Estudios Peruanos (Institute for Peruvian Studies), scoured the two main national newspapers for public opinion, and attended conferences and other events on the topic of socially inclusive development. Much of the narrative that I encountered from high-level Juntos affiliates conveyed the idea that Juntos was a largely successful program for delivering rights and citizenship to the rural poor. My interest in the gendered impacts of the program was met mainly with curiosity and sometimes with contempt; one policy administrator at MIDIS exasperatedly explained to me that Juntos was intended to benefit children, not women. Staff at the Ministry of Women and Vulnerable Populations and the influential national women's organizations told me about being excluded from the policy design and operational decisions regarding Juntos. This reality was an obvious source of contention and, in their opinion, explained a number of program flaws. The tension caused by the relative absence of engagement with the question of gender in spaces of policy making and administration would later inform my analysis of what I found in the communities where Juntos intervened.

I chose to conduct the portion of my fieldwork with Juntos recipients in the region of Cajamarca because it had the largest number of Juntos recipients, it was one of the top five poorest regions in the country, and most Cajamarcans speak Spanish as their first language (rather than an indigenous language), which would allow me to conduct all of the interviews myself. Upon hearing that I was interested in Cajamarca, staff at MIDIS tried to convince me to conduct my research elsewhere, suggesting instead two provinces in the central Andes where, in their words, I would see traditional indigenous communities in which Juntos had been highly successful. Cajamarca, they told me, was not actually poor. This assertion was commonly made by high-level policy staff in Lima. It was almost always connected to a disdain for the communities of politically engaged Cajamarcans who protested the local environmental and social abuses of the powerful extractive industry. After discussing the decision with local researchers and NGO staff, I 
decided to proceed with my study in Cajamarca, although this meant that my contacts at MIDIS no longer answered my emails and I was left to find another way into local-level program research.

Development organizations are often difficult for researchers to access without the support of a "gatekeeper" (Willis 2006), and I needed to find one of these in an area where Juntos intervened. In Cajamarca, Lewis Taylor, a British sociologist with a long history of research in the region, generously invited me to a fiesta at his house, where he introduced me to a host of other researchers, health-care and NGO staff, and other local authorities, many of whom came to be research participants or gatekeepers in my study. One of these was a judge who eventually put me in contact with the regional administrator for the Juntos program. The administrator invited me to the regional office and excitedly and patiently explained the ins and outs of program implementation. He also introduced me to the district and local managers, whom I eventually "job shadowed," following them around the districts they managed and as they completed administrative work and sent the mothers' compliance data to Lima.

I had initially assumed that, in Cajamarca, I would make contact and build relationships with Juntos recipients through program channels. This assumption was deflated very early on. I had been invited by a local manager to accompany him to a meeting of Juntos recipients in a tiny village called Tinca. At the meeting, he introduced me as "Doctora Tara," explaining to the room full of watchful mothers that I was working with the Juntos program and would be going around, house to house, "making sure that the mothers were meeting program conditions." I had not, of course, suggested anything of the sort. It was clear to me that for the mothers in the room, I was as good as a Juntos employee, the panicked expression on my face notwithstanding. As a result, it seemed all too certain that no one from that community or the surrounding villages was going to share with me her honest experiences of the Juntos program. I learned at least two important lessons in that moment-one, that I needed to be much more clear about my intentions, and two, that I was going to have to pivot in my research design.

Starting the next day, I began dividing my time between two distinct districts where Juntos intervened, focusing on the implementation practices of Juntos staff in one district and on building relationships with Juntos mothers and their families in the other. This is not to say that there was no overlap; I eventually interviewed local managers and related local authorities from both districts, and I spoke with Juntos mothers in both districts too. What this bifurcated approach permitted me to do was build trust with Juntos mothers in a way that would not have been possible otherwise. Let me illustrate, with another example, why this was important.

At the same fiesta where I established a connection to the regional Juntos office, I met Carla, who ran a number of grassroots projects oriented to meeting the needs of women and their families. Carla took me to a community where she used to work and had maintained a close relationship with a number of women, all of 
whom were Juntos recipients. She introduced me to some of these mothers and arranged my first interview with a Juntos recipient, a woman named Luz who traveled into the city every Saturday to clean the house of a middle-class Cajamarcan family. This early interview confirmed a number of hunches. The first was that I was going to have to establish a great deal of trust with the Juntos recipients I hoped to interview. Even though I had met Luz through a contact who was not related to Juntos, it was obvious that the responses she gave me were censored and shaped to present a rather more simplistic experience than that which I had begun to observe. It seemed to me that from Luz's perspective, I was interviewing her to find out if she was responsibly fulfilling her obligations as a Juntos mother.

Second, I realized that my carefully crafted interview script was not going to capture the contradictory dynamics that I was starting to observe in Juntos communities. For instance, why and how did Juntos mothers come to believe that in order to receive the cash payments they were required to grow gardens, participate in parades, and cook (unpaid) for the school lunch program-when none of these activities were officially mandated by program headquarters in Lima? These activities were a result of some of the obvious power dynamics at play that were not captured in the enormous body of CCT evaluations or present in the dominant narratives about program effectiveness.

Two months into fieldwork, frustrated and rather sure that my research was going nowhere, I explained the situation to a dear friend and colleague, Emily, over Skype. Her response-“Well, it sounds like you're doing institutional ethnography. Have you heard of Dorothy Smith?" - changed the course of my research. I immediately had Smith's and other institutional ethnography texts shipped to Cajamarca. Institutional ethnography is an explicitly feminist method of inquiry that illuminates how institutions organize people's everyday lives. ${ }^{13}$ Smith developed institutional ethnography in response to what she identified as "the deep opposition" between the branch of mainstream sociology she had been taught as a $\mathrm{PhD}$ student and the deeply experiential political practices she discovered in the women's movement (Smith 2005). Rather than testing "expert"-generated theories or hypotheses, institutional ethnography strives to generate knowledge that is grounded in the standpoint of daily life. ${ }^{14}$ Smith explained the distinction as follows:

To write a sociology from people's standpoint as contrasted with a standpoint in a theory-governed discourse does not mean writing a popular sociology. Though it starts from where we are in our everyday lives, it explores social relations and organization in which our everyday doings participate but which are not fully visible to us. The work of discovery sometimes calls for research that is technical and conceptually outside the everyday language of experience; at the same time, it has been our experience that once the institutional ethnography is completed, it becomes a resource that can be translated into people's everyday work knowledge. Hence it becomes a means of expanding people's own knowledge rather than substituting the expert's knowledge for our own (Smith 2005, 1). 
Central to institutional ethnography is a feminist attention to the work performed by people situated throughout the institution. Work is defined generously to include paid and unpaid labor alike. I approached the unpaid activities of Juntos mothers as work, including their efforts to meet program conditions and collect the payment, and the caring labors they carried out in households and community centers.

I also attempted to account for the work practices and processes of as many other institutional actors as possible; this included policy makers, program administrators, health-care staff, teachers, census takers, and regional Juntos staff. All of these actors (and indeed, many others) perform work upon which an efficiently functioning CCT program depends. During my research, I paid particular attention to the way that bureaucratic administrative tasks like checking boxes and filing paperwork connected the work of rural Juntos mothers to the decisions, actions, and inactions of more powerful actors in urban office buildings and boardrooms. My analysis thus stretched out from the local site of women's experiences and further and further into the many veins of the institution, tracing these connections at each stage to shed light on how the experiences of Juntos mothers were organized by social, political, and economic relations largely invisible to them.

There are institutional ethnographies of health care, education, and international aid; this book presents, to my knowledge, the first institutional ethnography of a CCT program. Over the course of ten months, in locations ranging from foggy Lima to the sparsely oxygenated communities of the northern Andes Mountains, I mapped the implementation of Peru's CCT program, holding women's experiences at the center of my inquiry. I triangulated the information I collected from differently situated actors through observation, semistructured and informal interviews, focus groups, and textual analysis. In Lima, I interviewed high-level decision makers, including the minister of the Ministry of Development and Social Inclusion; the executive director of Juntos and members of the now defunct Juntos Executive Committee; policy and program administrators at MIDIS and Juntos headquarters; and actors at major women's organizations, including the vice minister of the Ministry of Women and Vulnerable Populations and the executive directors at Flora Tristan and Manuela Ramos, the two largest nongovernmental organizations serving women in the country.

At the Juntos regional headquarters in Cajamarca, I interviewed the regional director, the district coordinator, and the four local managers overseeing the districts in which I conducted fieldwork. I accompanied local managers on most of their major work practices, including hosting community meetings, auditing household compliance with conditions, and entering data into the computer system. I also attended a regional staff training. To gain a better understanding of how the government targets the CCT program, I conducted participant observation with the regional census team as they prepared a community for a forthcoming survey. 
In the communities where Juntos intervened, I interviewed health and education staff and substituted for an absent English teacher over a three-week period at a local high school, an experience that gave me valuable insights into the quality and availability of education services. I attended meetings with Juntos recipientvolunteers called Mother Leaders, sat in on sewing circles, played with children, accompanied women while they harvested alfalfa and quinoa, and generally hung about. I conducted my most substantive interviews with Juntos mothers at the tail end of my fieldwork, once I had established trust and was able to ask questions grounded in the many dynamics I had observed over the previous seven months. ${ }^{15}$

Institutional ethnography allowed me to make a number of empirical discoveries grounded in the everyday experiences of women who receive conditionally provisioned social support. In the next section, I introduce a few concepts that are vital for making sense of these findings.

\section{CONDITIONS IN CRITICAL PERSPECTIVE}

In the following sections I introduce two critical conceptual tools that informed my fieldwork and have guided my analysis. The first of these is a feminist ethic of care-an approach to understanding the world that recognizes the centrality of caring to healthy and productive individuals and societies. The second conceptual tool is power-or more specifically, the disciplining power of governing techniques, especially when these are used to improve the well-being of populations. I introduce care and power here in order to help the reader trace them as connecting threads that run through the subsequent chapters, and through the future research and practical policy experiments that I hope this book will inspire.

\section{Care}

Care is difficult work, but it is the work that sustains life.

JOAN TRONTO, MORAL BOUNDARIES, 1993

While both men and women all over the world experience poverty, women experience poverty at higher rates than men, especially as mothers (UNDP 2003; UN 2015). One of the driving factors of this gendered disparity is the unequal distribution of care work. ${ }^{16}$ The term care work signifies the labor involved in the direct care of persons, in both paid and unpaid capacities (see Razavi 2007a). Care work is "work" because caring requires expenditures of time and energy. ${ }^{17}$ It includes activities that involve direct physical contact and emotional connection, such as feeding, bathing, consoling, encouraging, teaching, and accompanying dependents on visits to the doctor. Some activities, like shopping, washing clothes, cleaning, and preparing meals, are related to care work because they create the preconditions for caregiving (figure 4). They are imperative components of providing care even though they may be done without physical proximity to dependents (Razavi 2007a, 6). 


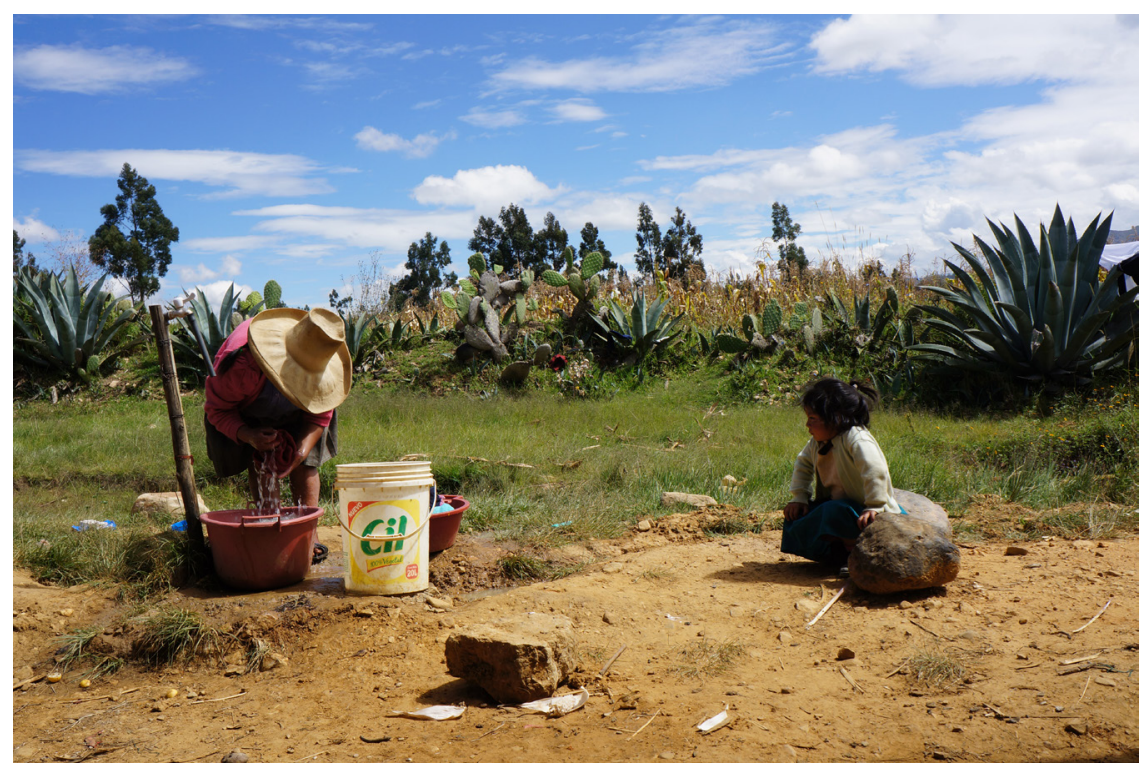

FIGURE 4. Juntos recipient Luz performing care work. Photo by the author.

Feminist economists have illustrated the ways in which care, far from being optional, is inseparable from all dimensions of development. Care is essential for human survival, affects the availability and quality of the productive labor force, and influences the rate of economic development (Razavi 2007b, 379). Economist Susan Himmelweit contends that it is unrealistic for development policy to ignore care work, because the decisions that ordinary people make about care work and seeking paid employment are inseparable. She is worth quoting at length: "There is increasing recognition that such decisions not only have short-term impacts on the labor market and the economy as conventionally understood; they may have even more important long-term implications for society as a whole, because the quality of care affects the type of workforce an economy can look forward to in the future, the supportive relationships that can be sustained between generations and the social values that can be maintained" (Himmelweit 2005, 2). In other words, care is necessary for the development of human capital. Questions about who gives care, who receives care, and who finances care work are central to the effectiveness, sustainability, and fairness of development policy. ${ }^{18}$

While the benefits of care work are dispersed broadly and profit society as a whole, the costs of caring are disproportionately borne by women (Razavi 2007a, 12). Of course, who does care work and how it is financed varies historically, regionally, and culturally. Care is provided by a variable and shifting combination of actors, including individuals, community organizations, the state, nonprofit organizations, 
and markets. ${ }^{19}$ While the gendered division of care work varies from context to context, women tend to do more paid and unpaid care work all over the world. To be sure, some caring labors, such as childbirth and nursing, are tightly bound to the natural bodily functions of womanhood. Yet outside of these, the lifelong gendered disparity in responsibility for care has precious little to do with biology. Rather, arbitrary social and political norms describe caring as women's work.

The distribution of care work has serious implications for the well-being of caregivers. Care ethicist Joan Tronto suggests that "caring is often constituted socially in a way that makes caring work into the work of the least well off members of society. ... [I]f we look at questions of race, class, and gender, we notice that those who are least well off in society are disproportionately those who do the work of caring, and that the best off members of society often use their positions of superiority to pass caring work off to others" $(1993,113)$. By attending to questions of care, "we are able to cast in stark relief where structures of power and privilege exist in society. Because questions of care are so concrete, an analysis of who cares for whom and for what reveals possible inequities much more clearly than do other forms of analysis" (Tronto 1993, 175).

While women do more care work than men across the developed and developing world and in urban and rural spaces, economic and social policies do shape the circumstances of care and who performs it. For instance, when governments make cuts to social services, paid care work that was performed by women in the public and private sector, such as in health clinics and day-care centers, becomes unpaid care work carried out by women in households and, in some cases, community centers. In places where government investment was never adequate, women have always accomplished the survival of their families through unpaid care work in their households and communities. The social policy architecturewhat social services are available and who they target-influences the gendered face of poverty. As Shahra Razavi, chief of research and data at UN Women, once put it, "How society addresses the issue of care has significant implications for the achievement of gender equality, by either broadening the capabilities and choices of women and men, or confining women to traditional roles associated with femininity and motherhood" (Razavi 2007b, 379). While less often discussed, the pervasive idea that care is "women's work" also prevents men from accessing purpose and identification as loving fathers and carers within their families and communities. ${ }^{20}$

In this book I am particularly interested in the relationship between social policy and unpaid care work. While unpaid caring typically takes place in households and between family members, it also occurs between friends, neighbors, and community members and in public, private, and nonprofit settings outside the home, such as community centers, soup kitchens, and day-care centers. Unpaid care work is not remunerated-which is not to say that it occurs without a cost. ${ }^{21}$ Unpaid caregivers shoulder financial obligations and must cope with forgone 
wages and missed opportunities (Folbre 2006). The amount of time required to accomplish care work influences whether an unpaid caregiver is able or willing to engage in paid employment (Himmelweit 2005, 19). This varies by context: while technological advancements have made washing clothes and dishes and preparing meals much quicker in developed countries, low-income and rural households in developing countries are unlikely to have access to these amenities. Access to paid domestic labor and well-developed infrastructure-such as potable water, electricity, and transportation that enables individuals to travel to grocery stores and pharmacies-also affects the amount of time spent on unpaid care work. ${ }^{22}$ The amount of unpaid care work women perform is largely hidden; this is because it typically takes place in the private sphere (i.e., households), and because it is not recognized as "productive" labor in most aggregate measures of economic activity, such as the gross domestic product. ${ }^{23}$

CCT programs reorganize care in a way that experts believe will best produce future citizens equipped with the skills and good health to participate in the labor market and contribute to and benefit from economic development (see Ruckert 2010). For the most part this is done without any explicit acknowledgment of the role of unpaid care and unpaid caregivers in the success of these programs. In an attempt to correct what I show is a harmful omission, the chapters that follow draw attention to the technical realms-policy documents and auditing measures-that are conspicuously inattentive to the spaces in which care is accomplished and to the mothers responsible for caring. This conceptual grounding in care is imperative to making sense of the empirical evidence I present about the hidden costs and unjust outcomes wrought upon women when aid is made conditional.

\section{Power}

An accepted and reasonable conclusion to draw from a review of the quantitative evidence on CCTs is that they are powerful tools for changing poor people's lives for the better. It is far less common to think of CCTs as a means for exercising power over the desperately poor. Very little is known about specifically how CCTs achieve the high rates of compliance that they do. This question, while infrequently asked, is important because the populations targeted by CCT programs are among the most marginalized and vulnerable. While behavioral economics is interested in the mechanics of achieving behavioral change in individuals and groups, it does not tend to dwell on the broader social implications of these mechanisms. CCTs are a governance mechanism; they are a tool used to shape the behavior of certain populations to produce a desired outcome. It is worth considering, and I do so over the following chapters, the coercive power of incentives. I set up this notion - of the coercive power of incentives - early in the book in order to train attention on the unintended and sometimes unjust effects of conditional aid, and I hope that it will be a useful framework for interpreting the evidence I present in each chapter. 
To understand the social implications of conditionality, I turn to critical development studies, and to a particular body of work that treats governing as a set of activities through which power dynamics are produced and reinforced (Ferguson 1990; Rankin 2001, 2002; Englund 2006; Li 2007). Governmentality studies explore the sometimes obvious, often subtle mechanisms used to shape the behaviors of populations to create a desired outcome, whether better health, higher literacy rates, or rural development. Governance interventions are typically driven by a concern for the well-being and prosperity of individuals and populations (Foucault et al. 1991). Regardless of intention, governing the behavior of others necessarily involves an exercise of power (Foucault 1982). Power is often exercised in mundane and barely visible ways: "At the level of population, it is not possible to coerce every single individual and regulate their actions in minute detail. Rather, government operates by educating desires and configuring habits, aspirations and beliefs. It sets conditions, 'artificially so arranging things so that people, following only their own interest, will do as they ought'" (Jeremy Bentham, quoted in Li 2007,5 , original emphasis). This is not to say that government interventions force unwitting or helpless individuals to do things that would otherwise be of little or no personal interest.

Take, for instance, the issue of smoking. Fifty years ago, smoking was not merely permissible but fashionable. Today, equipped with research proving the harmful impacts of tobacco use, authorities in government and health institutes devise large-scale interventions to prevent addiction and curb consumption. The grotesque photographs printed on cigarette boxes and billboards in some countries and the regulations restricting smoking in restaurants, airplanes, and some parks communicate that smoking is not only unhealthy but also disgusting and antisocial. While these governance mechanisms do not succeed at modifying the behavior of all smokers everywhere, they have been highly effective at "educating desires and configuring habits, aspirations and beliefs" on a large scale. Many people who quit smoking and enjoy better health likely feel grateful for the intervention. Many nonsmokers do too; having prior knowledge of smoking's adverse impacts, they never took up the habit in the first place and can now enjoy smoke-free public spaces. The smokers who resist changing their behavior might resent being labeled as disgusting or having their freedom restricted in public places. They might also contest the authority or legitimacy of public health experts to govern their lives. This example draws attention to a key insight from governmentality studies, which is that governance involves an exercise of power.

The regulation of smoking is a relatively positive example, but there have been many other attempts to improve a given population's health and well-being that illustrate the darker and less subtle ways that power can operate. In Peru in the late 1990s, the Fujimori government staged a large-scale family-planning intervention intended to alleviate poverty in rural indigenous communities. With funding from the United States government (the US Agency for International Development) and 
the support of Peruvian national women's organizations, the campaign sought to increase poor people's access to a range of contraceptives, including voluntary surgical contraception (sterilization). Yet individuals in the poor and mostly rural indigenous communities targeted by this program reported that in some cases, local health professionals persistently pressured them to undergo the sterilization procedure. Other female victims described being forcibly restrained and anesthetized after giving birth, at which point health staff performed the procedure without the woman's knowledge or consent. ${ }^{24}$ Over a four-year period, between 260,000 and 350,000 mostly indigenous women and some men were forcibly sterilized (Boesten 2010). This example, while extreme, highlights the potential for purportedly well-intended governance interventions to operate through coercive power-to devastating effect.

This critical analysis of power and governance has a number of implications for how we understand the use of conditions to alleviate poverty. Shaping the behavior of populations to create a desired outcome is precisely the work CCTs are deployed to do. In order to explain how power operates in programs that implement conditions, I draw on two related conceptual tools from governmentality studies. The first concerns discipline, by which I mean the regulation of behavior (Foucault 1977). In a number of institutional settings, governments discipline individuals' behavior by regulating how and where they spend their time and how they move their bodies. Social scientists have shown that discipline is often accomplished through use of surveillance. French philosopher Michel Foucault wrote about institutionalized discipline in the prison system (Foucault 1977). In prisons, the government regulates the behavior of inmates by controlling the spaces they can access, the schedules they follow, and the activities in which they can and cannot participate.

When a government disciplines the behavior of individuals, it exercises power. This is not to say that power is only ever top down. The people whose behavior is being disciplined also deploy tactics of resistance (Scott 1985; see also Li 2007). Of course, the prison is an extreme example. But disciplinary power functions in many institutions where authorities seek to create high-functioning, productive citizens, including schools, factories, and welfare programs. In this study of CCTs, the notion of discipline trains our attention to the ways that authorities regulate the behavior of rural mothers by imposing a schedule of conditions, closely monitoring these women to ensure that the conditions are met and levying sanctions when they are not. It also trains our attention to the unequal power relationship between development experts and the poor mothers who are subject to their expertise. While studies of development often focus on the purported deficiencies of the poor, my purpose is to draw attention to the power-laden relationship between poor mothers and the policy makers, technocrats, and frontline program implementers who set and enforce program conditions, shining a light on how these relationships shape the experiences of CCT recipients. 
If CCTs discipline women to act in accordance with a governance project, a related question concerns the intentions and outcomes of the project itself. A handful of studies have drawn on theories of governmentality to show that CCTs are intended to produce compliant, productive female subjects who mother responsibly and interact, often for the first time, with financial markets (Luccisano 2006; Hossain 2010; Meltzer 2013). I am interested in the productive work of CCT programs that is unintentional and that largely goes unseen. Attempts to govern rarely work out precisely as planned, and even the best-intended and well-funded development interventions frequently fail to meet their original stated aims. ${ }^{25}$ Even when they do succeed, well-intended interventions generate unintended consequences. Social scientists have shown that routine failures and unintended consequences are not aberrations of the development process but, rather, a logical outcome of what happens when planned development interventions encounter the messy, lived world of politics, bodies, social relations, and environment that may not have featured in program design (Ferguson 1990; Li 2007).

When experts in institutions like government bureaucracies, think tanks, NGOs, and private foundations are tasked with solving problems of poverty, their analyses and proposed solutions often favor a nonpolitical, technical approach that avoids grappling with the seemingly intractable political and economic structures and systems that drive and sustain inequality (Ferguson 1990; Li 2007). Anthropologist of development Tania Li calls the practice of framing questions of poverty, inequality, and ill health in apolitical terms "rendering technical" ( $\mathrm{Li} \mathrm{2007).{ } ^ { 2 6 }}$ This term is useful because it draws our attention to what experts include and exclude when they make decisions about what needs to be improved and how. Apolitical, technical problems beget apolitical, technical solutions. As a result, interventions devised for an issue that has been rendered technical often focus on reconfiguring the capacities and behaviors of poor people instead of transforming the political systems and economic policies that keep some people rich and others poor (Li 2007, 7).

CCTs are one such example of a depoliticized, technical development approach. The programs are premised on the assumption that poverty is the result of misguided individual choices, a problem that has been matched with the technical solution of incentivizing children's mothers to make better choices. While use of health and education services certainly plays a role in improving life outcomes, a number of relevant political questions that locate the drivers of poverty outside of the household are excluded from both the framing of the problem and its solution. Take for instance the availability of decent paid labor, or inequitable patterns of investment in education, health care, and infrastructure across rural and urban spaces. By excluding political-economic drivers of poverty in the design of this intervention, CCTs frame poverty as a result of the irresponsible behavior of individual mothers (Molyneux 2006; Bradshaw 2008).

This framing and the disciplinary practices that CCTs sanction produce a number of unintended consequences for the poor mothers who are targeted by cash 
transfer programs. The first is extensive care work. Chapters 3 and 4 illustrate how mothers are disciplined to comply with program conditions, only to find themselves in the ironic situation of taking their children to underfunded and shortstaffed schools and health clinics that are not equipped to deliver an adequate level of service. The state wastes women's time by requiring them to walk and wait for services that are sparsely distributed and often difficult to access in the rural countryside. The technical manner in which CCTs are monitored and evaluated makes women's extensive care work invisible; there are no questions asked about the availability and quality of services, or about what is required of women to access them.

In chapter 6, I show that mothers comply with a host of shadow conditions imposed on them by CCT staff, teachers, health professionals, and local government, all of whom have the institutionally sanctioned power to do so. The CCT disciplines women's behavior to the extent that they comply because it is the reasonable thing to do, despite the demands on their time, well-being, and dignity that many of these shadow conditions entail. While these unforeseen outcomes are certainly unintended, they should not be treated as aberrations. Rather, these hidden costs are a logical outcome of imposing conditions in a place where the state fails to adequately invest in health care, education, and infrastructure, and where urban, "whiter" professionals have more power than poor, indigenous, rural women beneficiaries. The unintended consequences discussed in this book are rarely captured in mainstream program evaluations, in large part because they fall outside the technical boundaries drawn around the problem and its solution-few evaluators are looking for them.

I had some reservations about drawing on governmentality theory. Many governmentality studies are based on textual analyses that can miss the messiness and contradictions of processes of implementation and resistance (Pat O'Malley et al. 1997, cited in Rankin 2001, 23). As a result, analyses in this field are susceptible to totalizing accounts that leave little room for pragmatic responses or even hope. As someone who insists on bridging the seemingly separated spaces of academy and policy, I find that pragmatism and hope are essential. Many scholars of governmentality maintain that coming up with "improved" policy proposals is not the purpose of critical studies, and that critique for critique's sake is essential. I do not disagree with this. On the other hand, it is difficult to study CCTs and not think about the dynamics of power that governmentality studies theorize so well.

Is there a place for critically oriented studies of policy? I position myself within a contingent of critical-development-studies scholars who suggest that there is. Geographer Katherine Rankin makes a case for using ethnographic methods to enrich our understanding of governmental strategies. She suggests that starting our inquiry "from the standpoint of the oppressed" provides a basis for challenging dominant regimes of power (Rankin 2001, 23). And Li reflects on the imperative to challenging hierarchies of expertise: "This is the purpose of critique: not 
to replace government by something else, as yet undefined, but to 'enhance the contestability of regimes of authority that seek to govern us in the name of our own good' (Rose 1999, 59), to question truths not in the name of greater or final truth but as a matter of continuous vigilance" (Li 2010, 3). My hope for this book is that it advances a critical account of a well-intended development intervention that doesn't paralyze but, rather, prompts difficult reflection and radical imagination for a more just future.

\section{CONTRIBUTIONS OF THIS BOOK}

This book makes three central contributions to development and social policy studies, through an analysis of conditional cash transfers that accounts for care, power, and geography. The first is an understanding of how conditional aid is implemented. Most academic and policy research studies examine the impacts or outcomes of development interventions; far fewer investigate the practices and processes of implementation. Yet it is at the level of implementation that we are able to capture hidden or unexpected dynamics of how outcomes are produced. This gap has led social scientists to call for additional meso-level accounts of development that illustrate how interventions function across scales and that offer detailed explanations of social change (Currie-Alder 2016).

This book situates cash transfer recipients' experiences within a much broader web of practices, processes, and decisions that stretch across time and space, linking Andean households to clinics and schools and to offices and boardrooms in far-away Lima. The focus on implementation allows our understanding of CCT outcomes to be informed by the social and geographical contexts in which Juntos operates. Implementing policy across unevenly developed and rugged territory is no simple feat, and the challenges posed by geography necessarily shape how the work gets done. Frontline program workers, health and education staff, and local government authorities easily escape studies that focus solely on program outcomes within households. In contrast, a focus on implementation reveals these myriad actors, their work, and the context in which they do it as key determinants in women's experiences of development. In this way, the book is less concerned with if conditionality works and instead illustrates how conditionality works.

The second contribution of this book is an evidence-based challenge to the "measurement imperative" pervading the contemporary study and practice of development. The dominant trend in development studies demands quantitative evidence of impact on specific aspects of human well-being. Randomized control trials are the measurement tool par excellence, with proponents insisting that this method is synonymous with rigor (Karlan and Appel 2011). Yet this preoccupation with quantification stands at odds with many of the concerns of feminist scholarship, including the much messier and harder to quantify stuff of social relations, 
intersecting inequalities, and power (Buss 2015). This book brings ethnographic evidence and an analytic focus on care, power, and geography to bear on dominant data trends.

Most analyses of CCT programs are aspatial, neglecting to account for the landscapes over which implementation occurs (Ballard 2013). In contrast, this book provides an illustration of what happens when technical interventions and the metrics that feed them do not account for the landscapes that women traverseand the labor it takes to do so. In this way, it reveals the hidden costs of a narrowly quantitative approach to measurement and evaluation that renders invisible women's extensive care burden and the deeply rooted social and economic drivers of poverty.

Finally, this book contributes a "thick description" (Geertz 1973) of the hidden costs of women's participation in conditional cash transfer programs. In a number of nonfeminist circles, a common response to my research has been: "Oh, CCTs, but there is so much data on those!" The review of data that I presented above indicates that, to an extent, this is true. Yet there is a very real difference between sex-disaggregated data and a gender analysis. While there is plenty of sex-disaggregated data on CCTs that provide us with important indicators like how many girls versus boys attend school, there are far fewer gender analyses examining how CCT programs not only affect the social and material inequities between women and men but also explain why such inequalities exist and what it might take to undo them.

The research in this book builds upon the seminal feminist work on CCT programs that unpacked a number of normative implications of the programs and, in particular, disrupted the widely held assumption that giving cash to women is a straightforwardly empowering feature of policy design (Molyneux 2006; Bradshaw and Víquez 2008; Tabbush 2009). The ethnographic evidence presented in the following chapters puts flesh on the bones of these important arguments. The seemingly mundane details of mothers' walking and waiting, interactions with local authorities, and participation in shadow conditions illustrate the coercive power of incentives and the ultimately unjust conditions fostered by this fashionable mechanism for development.

In the chapters that follow, I present an analysis of conditionally provisioned aid that is alternative to mainstream accounts in terms of both methodology and conceptual approach. It is a view from the margins. With this book, I hope to provoke a broader discussion about how we approach care and what that means for the people who provide it, most of whom are women. I also hope that this discussion spans the oft-disconnected realms of policy making and academic research. I have conducted research and participated in projects of improvement in both worlds and have seen firsthand the dire need for these two communities to be in productive conversation. 


\section{CHAPTER OUTLINES}

The next chapter in this book illustrates how a narrowed focus on a handful of quantitative metrics permitted the substance of a well-intentioned social policy to be evacuated. The chapter is situated in the air-conditioned office buildings and conference rooms of Lima, where development experts at Juntos and MIDIS make decisions in the context of a global "measurement obsession" (Liebowitz and Zwingel 2014). Policy makers spoke to me about the state's responsibility to provide poor people with quality health and education services, which they knew the state did not provide. Yet by narrowing program focus to conditionality, they were able to produce impressive statistics related to service uptake and present Juntos as a success story. By depoliticizing and rendering technical (Li 2007) the problem of poverty, policy makers set into motion a set of processes and practices that masked the very exclusions Juntos sought to redress.

Set in the more isolated areas where Juntos intervenes, chapter 3 uncovers the ironic impacts of conditioning aid in underdeveloped places. It addresses two questions: why do poor, rural people not attend health and education services of their own volition? And when the cash incentive does drive the intended behavioral changes, what do poor women and their children encounter at schools and health clinics? By documenting the everyday ordeals rural mothers face in meeting program conditions, this chapter sheds light on what statistical evaluations fail to capture: institutionalized discrimination and the uncomfortable realities of poorquality services. I argue that in making aid conditional, the state-ironicallycompels women and children to confront the material realities of their exclusion.

Chapters 4, 5, and 6 explore the gendered dimensions of power to which conditionality gives rise. In chapter 4, I explore rural women's mobility and access to state services and how these are exacerbated by the demands of the CCT. Rather than the smooth surfaces, simplistic transactions, and easily mobile development subjects presumed by policy makers, the experiences of CCT recipients reveal uneven geographies and the embodied, tedious work of "walking and waiting." I contend that the requirement that women walk and wait for assistance from the state effectively "puts them in their place," reminding them of their lowly social status.

Chapter 5 further explores the various forms of additional labor women perform to make the CCT an "efficient" program. Local managers rely on both support from clinic and health staff and a select group of CCT recipients called Mother Leaders to aid them in enforcing conditions. While reliance on such help was unplanned at the national level of policy making, I show how Juntos is unviable without the work of these women. With this detailed analysis of the slippages between paid and unpaid labor on the frontline state, I offer a window into the gendered assumptions underlying so-called inclusive development, laying bare a reliance on women's time and willingness to discipline their neighbors to make up for persistent underinvestment in public institutions and services. 
Chapter 6 documents and analyzes the myriad additional tasks that women perform as Juntos recipients, above and beyond the officially required program conditions. I refer to these tasks, which also feature in other CCTs, as "shadow conditions." While they are invisible in official documents, these activities are integral to program implementation and experienced by Juntos mothers as part and parcel of their coresponsibilities. This chapter illustrates how in the real world of bodies, uneven development, inequality, and discrimination, conditionality becomes a tool for various, more powerful groups to implement their own projects of improvement among less powerful groups.

In the conclusion, I reflect on what a conditional approach to aid means for social policy and development more broadly. Dominant actors in international development and global health urge the implementation of "adequate" cash transfer programs to enhance human capital, eradicate poverty, and reduce inequalities. Yet poor, rural women's experiences illustrate that conditionality is an unjust means for achieving these goals. I consider here how women's experiences might reorient optimistic discussions about the potential for unconditional cash transfers to drive what some have imagined as a "new politics of distribution" (Ferguson 2015). As I argue in this book, without a substantive investment in improving the basic conditions of people's lives, cash only alleviates some of the costs of caring. 